\title{
ON THE UNIQUENESS OF MACROECONOMIC EQUILIBRIA WITH QUANTITY RATIONING
}

\author{
Volker BÖHM \\ University of Mannheim, D-6800 Mannheim, West Germany
}

Received 29 April 1982

This note provides an elementary proof of uniqueness of macroeconomic equilibria with rationing for economics with two traded commodities and fixed prices.

\section{Introduction}

In two independent contributions by Muellbauer and Portes (1978) and in the habilitation monograph by the author submitted in 1977 and published in 1980, a macroeconomic model with quantity rationing was described which allows producers to hold inventories as well as money halances. In both papers the discussion of comparative statics properties depends crucially on an asserted uniqueness result which is not proved in either publication. This note gives an elementary uniqueness proof. The gencral casc with an arbitrary number of commoditics is treated in Kosch (1981).

\section{The model}

Given the data of the economy, the consumption sector including government purchases can be described by the effective commodity demand function

$X=C_{u}(L)$ 
and by the effective labor supply function

$L=A_{x}(X)$

satisfying for some $L^{*}>0$ and $X^{*}>0$

(i) $X^{*}=C_{u}(L) \quad \forall L \geqslant L^{*}$,

(ii) $L^{*}=A_{x}(X) \quad \forall X \geqslant X^{*}$.

$\left(X^{*}, L^{*}\right)$ is the pair of unconstrained decisions (i.e., the notional demand and supply) of the consumption sector. Similarly, the production sector is given by a pair of effective demand and supply functions, relating sales $Y$ to labor demand $Z$,

$Y=G_{z}(Z), \quad Z=H_{y}(Y)$

satisfying for some $Z^{*}>0$ and $Y^{*}>0$

(iii) $Y^{*}=G_{z}(Z) \quad \forall Z \geqslant Z^{*}$,

(iv) $Z^{*}=H_{y}(Y) \quad \forall Y \geqslant Y^{*}$.

$\left(Y^{*}, Z^{*}\right)$ is the pair of notional supply and demand of the production sector. All variables and functions are assumed to be non-negative.

Let

$C=\left\{(X, L) \mid C_{u}(L) \geqslant X, A_{x}(X) \geqslant L\right\}, \quad$ and

$\boldsymbol{P}=\left\{(Y, Z) \mid H_{y}(Y) \geqslant Z, G_{z}(Z) \geqslant Y\right\}$

Then, the set of feasible states is $\boldsymbol{C} \cap \boldsymbol{P}$.

Definition. A feasible state $(X, L)$ of the exonomy of aggregate employment $L$ and aggregate sales $X$ is a Keynesian unemployment situation if it is a solution for

$$
\begin{array}{ll}
C_{u}(L)=X, & X<Y^{*}, \\
H_{y}(X)=L, & L<L^{*} .
\end{array}
$$

Definition. A feasible state $(X, L)$ is a repressed inflation situation if 


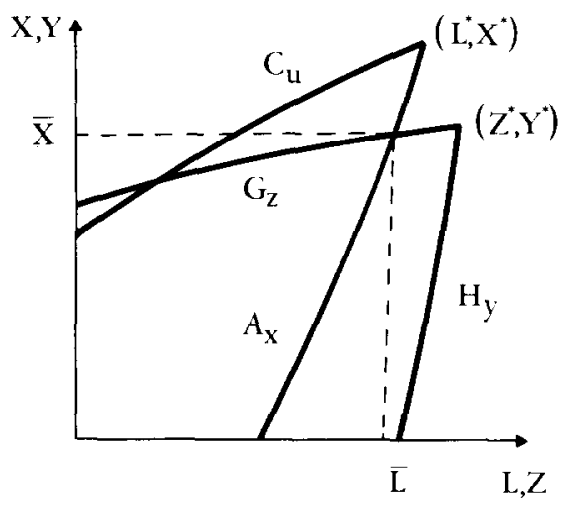

Fig. 1.

$(X, L)$ is a solution for

$A_{x}(X)=L, \quad L<Z^{*}$,

$G_{z}(L)=X, \quad X<X^{*}$.

Definition. A feasible state $(X, L)$ is a classical unemployment situation denoted $C$ if

$L=Z^{*}, \quad X=Y^{*}$,

$C_{u}(L)>X, \quad A_{x}(X)>L$.

Definition. A feasible state $(X, L)$ is a situation of underconsumption if $L=L^{*}, \quad X=X^{*}$,

$G_{z}(L)>X, \quad H_{y}(X)>L$.

A geometrical presentation of a typical disequilibrium situation is given in fig. 1, which depicts a situation where a repressed inflation state is obtained. $(\bar{L}, \bar{X})$ are the associated employment and sales levels. From the behavioral assumptions underlying the aggregate functions it follows that all acceptable states of a sector lie 'inside' the set formed by the wedge of the two functions. The acceptable sets are bounded and they 
are closed if the functions are continuous. Therefore, any disequilibrium state lies in the intersection of the two sets which is always non-empty since the origin belongs to both sets. Moreover, it is easy to see that at least one of the disequilibrium states will occur.

Theorem. Assume that the following conditions hold:

(C.1) $\quad C_{u}(0)>0, \quad A_{x}(0)>0$,

(C.2) $\quad C_{u}^{\prime}>0, \quad A_{x}^{\prime}>0, \quad C_{u}^{\prime} A_{x}^{\prime}<1$,

(P.1) $H_{y}(0)>0, \quad G_{z}(0)>0$,

(P.2) $\quad H_{y}^{\prime}>0, \quad G_{z}^{\prime}>0, \quad H_{y}^{\prime} G_{z}^{\prime}<1$,

(A) $\quad C_{u}^{\prime} H_{y}^{\prime}<1, \quad A_{x}^{\prime} G_{z}^{\prime}<1$.

Then, there exists at most one disequilibrium situation which has positive employment and positive sales.

Assumptions (C.1), (C.2), (P.1) and (P.2) are natural in the aggregate context here and they prevent boundary solutions. Assumption (A) was used in Böhm (1980) and Muellbauer and Portes (1978). It guarantees normal supply and demand multipliers. (A) can be weakened to piecewise differentiable functions which would be the more natural framework, since the aggregate effective supply and demand functions will typically be non-differentiable at a point where an individual agent changes from a situation of rationing to non-rationing.

Proof. Define $X=\min \left\{Y^{*}, X^{*}\right\}$ and $L=\min \left\{Z^{*}, L^{*}\right\} .(X, L)$ is a Walrasian state if and only if $X=Y^{*}=\bar{X}^{*}$ and $L=Z^{*}=L^{*}$. All other feasible states are such that $(\widetilde{X, L}) \leqslant(\underline{X}, \underline{L})$.

Let $A_{x}^{-1}$ denote the inverse of $A_{x}$ and $H_{y}^{-1}$ the inverse of $H_{y}$, both being defined on their appropriate domaines. Consider the four functions

$$
\begin{array}{ll}
U(L)=C_{u}(L)-A_{x}^{-1}(L) & \text { defined on }\left[A_{x}(0), \underline{L}\right], \\
C(L)=G_{z}(L)-H_{y}^{-1}(L) & \text { defined on }\left[H_{y}(0), \underline{L}\right], \\
K(L)=C_{u}(L)-H_{y}^{-1}(L) & \text { defined on }\left[H_{y}(0), \underline{L}\right], \\
I(L)=G_{z}(L)-A_{x}^{-1}(L) & \text { defined on }\left[A_{x}(0), \underline{L}\right] .
\end{array}
$$

It is easy to see from the assumptions of the theorem, that each of these 
functions is strictly decreasing and positive at the left end of its domain. Moreover, a feasible state of underconsumption, of classical unemployment, of Keynesian unemployment or of repressed inflation defines a zero of $U, C, K$ or $I$ respectively. It remains to be shown that, except for boundary cases, no two functions have a zero simultaneously for feasible pairs $(X, L) \in \boldsymbol{C} \cap \boldsymbol{P}$.

Suppose there exists a Keynesian state $\left(X_{k}, L_{k}\right)$. Then $L_{k}<L$ such that $K\left(L_{k}\right)=C_{u}\left(L_{k}\right)-H_{y}^{-1}\left(L_{k}\right)=0, U\left(L_{k}\right)>0$ and $C\left(L_{k}\right)>0$. Moreover

$$
\begin{aligned}
I\left(L_{k}\right) & =G_{z}\left(L_{k}\right)-A_{x}^{-1}\left(L_{k}\right) \\
& =G_{z}\left(L_{k}\right)-A_{x}^{-1}\left(L_{k}\right)+C_{u}\left(L_{k}\right)-H_{y}^{-1}\left(L_{k}\right) \\
& =U\left(L_{k}\right)+C\left(L_{k}\right)>0 .
\end{aligned}
$$

Since $I(L)$ is strictly decreasing, $I(L)>0$ for all $L \leqslant L_{k} . L>L_{k}$ represent infeasible states. Therefore, if a Keynesian solution exists, all the other three are excluded.

Suppose there exists an inflationary state $\left(X_{1}, L_{J}\right)$. Then $L_{I}<L$ such that $I\left(L_{I}\right)=G_{z}\left(L_{I}\right)-A_{x}^{-1}\left(L_{I}\right)=0$. Since $U\left(L_{I}\right)>0$ and $C\left(L_{I}\right)>\overline{0}$, one obtains

$$
\begin{aligned}
K\left(L_{I}\right) & =C_{u}\left(L_{I}\right)-H_{y}^{-1}\left(L_{I}\right) \\
& -C_{u}\left(L_{I}\right)-H_{y}^{-1}\left(L_{I}\right)+G_{z}\left(L_{I}\right)-A_{x}^{-1}\left(L_{I}\right) \\
& =U\left(L_{I}\right)+C\left(L_{I}\right)>0 .
\end{aligned}
$$

Monotonicity implies again that there is no other solution for $L \leqslant L_{l}$.

Suppose $\left(X^{*}, L^{*}\right)$ is an underconsumption state, i.e., $X^{*}=C_{u}\left(L^{*}\right)$, $U\left(L^{*}\right)=0$ and $L^{*}<Z^{*}$. Since $\left(X^{*}, L^{*}\right) \in \boldsymbol{P}$, one must have

$C_{u}\left(L^{*}\right)<G_{z}\left(L^{*}\right)$ and $C_{u}\left(L^{*}\right)>H_{y}^{-1}\left(L^{*}\right)$

Therefore

$I\left(L^{*}\right)=G_{z}\left(L^{*}\right)-A_{x}^{-1}\left(L^{*}\right)>C_{u}\left(L^{*}\right)-A_{x}^{-1}\left(L^{*}\right)=0$, and

$K\left(L^{*}\right)-C_{u}\left(L^{*}\right)-H_{y}^{-1}\left(L^{*}\right)>0$. 
Hence, monotonicity of $I$ and $K$ imply that there exists no other feasible solution. In a similar fashion one shows that, if $\left(Y^{*}, Z^{*}\right)$ is a classical state, there exists no other feasible solution. Q.E.D.

\section{References}

Böhm, V., 1978, Disequilibrium dynamics in a simple macroeconomic model, Journal of Economic Theory 17, 179-199.

Böhm, V., 1980, Preise, Löhne und Beschäftigung, Beitrag zur Theorie der mikroökonomischen Grundlagen der Makroökonomik [J.C.B. Mohr (Paul Siebeck) Tübingen].

Kosch, B., 1981, On the global uniqueness of fix-price-equilibria, Discussion paper no. 184-81 (Institut für VWL und Statistik der Universität Mannheim, Mannheim).

Muellbauer, J. and R.D. Portes, 1978, Macroeconomic models with quantity rationing, Economic Journal 88, no. 4, 788-821. 